numbers and size, occurred in the areas on which the drops were originally placed. Elsewhere the plaques were either very small or absent.

It was found that drops of cell-free milk serum produced the same effect and that the addition of $0.5 \mathrm{ml}$. of serum to $15 \mathrm{ml}$. of agar before pouring allowed good development of plaques all over the plate. Where previously the plaques had been less than $0.5 \mathrm{~mm}$. in diameter, addition of serum gave plaques up to $1.5 \mathrm{~mm}$. Unclarified agar also gave larger plaques with added serum.

Similarly, in a yeast extract lactose phosphate broth, in which phage development was not sufficient to produce complete lysis, addition of milk serum enabled lysis to proceed to completion and the broth became clear. Within limits, increasing amounts of serum produced more rapid clearing, at the same time forming an increasing amount of precipitate in the medium. On the assumption that the precipitate was calcium phosphate, calcium chloride was added and found to produce the same effect. Similarly, on agar calcium chloride produced a stimulation similar to serum.

Calcium has been found essential for the development of staphylococcal phage by $\mathrm{Smith}^{3}$ and for certain coliform phages by Delbrück ${ }^{4}$ and Doermann ${ }^{5}$. The well-known inhibition of certain phages by citrate is probably due to removal of calcium ions ${ }^{6}$. We have been able to reverse the stimulatory effect of calcium by addition of citrate.

The optimum amount of calcium chloride varies with difierent media, apparently according to phosphate content, and with the media used ranged from $0.02 M$ to $0.007 M$. Stimulation of phage development was produced with as little as $0.001 M$.

Eight phages for different strains of Streptococcus cremoris all need calcium for maximum development. Adsorption takes place without added calcium in yeast dextrose broth. Doermann ${ }^{5}$ found that adsorption of the coliform phage, $T 5$, could occur in the absence of calcium, but lysis did not follow. Delbrück $^{4}$ observed that calcium was essential for adsorption of a T4 mutant. As the broth used in the present work was not completely calcium-free, it is not clear whether calcium is essential for adsorption or for later stages in the lytic process. It has not been possible to stimulate phage development with magnesium ions in place of calcium ions.

Kraft Walker Cheese Co. Pty., Ltd.,

$$
\text { D. I. SHEW }
$$
Allansford,

Victoria, Australia.

${ }^{1}$ Nichols, A. A., and Wolf, J. Z., J. Dairy Res., 14, 81 (1945).

'Hunter, G. J. E., J. Dairy Res., 14, 283 (1946).

${ }^{3}$ Smith, H. W., Nature, 161, 397 (1948).

‘ Delbrück, M., J. Bact., 58, 1 (1948).

${ }^{5}$ Doermann, A, H., J. Bact., 55, 257 (1948).

- Rountree, P. M., Aust. J. Exp. Biol. Med. Sci., 25, 203 (1947).

\section{Role of the Intestinal Flora in the Develop- ment of Vitamin E Deficiency}

IN some experiments, white rats were given the following basal diet: glucose 70, purified casein 20, salt mixture 4, arachis oil $+1,600$ I.U. vitamin $\mathbf{A}$ and 150 I.U. vitamin D3, succinylsulphathiazole or phthalylsulphathiazole respectively 1 and vitamin mixture 2 (consisting of choline chloride $1 \mathrm{gm}$., nicotinic acid $50 \mathrm{mgm}$., thiamine hydrochloride $10 \mathrm{mgm}$., riboflavin $10 \mathrm{mgm}$., calcium pantothenate $50 \mathrm{mgm}$., pyridoxin hydrochloride $10 \mathrm{mgm} ., p$-aminobenzoic acid $10 \mathrm{mgm}$., vitamin $\mathrm{K} 5 \mathrm{mgm}$. and glucose to 20 gm.).

This synthetic, vitamin E-deficient diet was given to 40 rats aged four to five weeks, and after forty to fifty days a depigmentation, particularly of the orange-coloured upper incisors, occurred, as described by Moore $^{1}$. Histological examination of the incisors showed that the enamel organ had undergone some characteristic changes, consisting partly of a premature atrophy of the stratum papillare, and partly of the formation of cyst-like cavities in the ameloblasts.

If, however, vitamin $\mathrm{E}$ was given simultaneously in doses of $3 \mathrm{mgm}$. tocopherol daily, neither depig mentation of the incisors nor histopathological changes in the enamel organ occurred.

In a third experiment an amount of 20 per cent fæces from rats on a normal stock diet was added to the synthetic basal diet without vitamin E. In this case also no depigmentation of the incisors or histopathological changes in the enamel organ occurred.

On this basis it appears justifiable to assume that a bacterial synthesis of vitamin $\mathrm{E}$ takes place in the digestive tract of the white rat under certain conditions.

Biological Laboratories

J. J. PIndborg

of the Medicinalco, Ltd., and

Department of Histology, National Dental College of Denmark.

'Moore, T., Biochem. J., 37, 112 (1943).

\section{Inhibition of $R h$ Agglutination by Disodium Hydrogen Citrate}

IT was found that $R h$-positive (that is, $D$-positive) red blood cells suspended in an anti-coagulant preservative solution ( 2 per cent disodium hydrogen citrate or 'acid citrate'; $\mathbf{2 . 5}$ per cent dextrose) were not agglutinated by anti- $D$ grouping sera. Investigating this inhibition, 2 per cent $D$-positive cell suspensions were titrated with a strong anti- $D$ serum. The titre of cells in isotonic $(0.85$ per cent) saline and in isotonic ( 5 per cent) dextrose was 320 , but in isotonic mixtures of acid citrate and sodium chloride or dextrose the titre was reduced according to the acid citrate concentration.

In the accompanying figure, the results of titrations of cells containing the $R h$ factors $\mathrm{C}, \mathrm{D}, \mathrm{E}$ and $\mathrm{c}$ with corresponding anti-sera are shown, the titres given being the mean of at least three results. The acid citrate solutions were made isotonic with sodium chloride. The inhibition of agglutination occurs with acid citrate concentrations higher than $0 \cdot 1$ per cent, but the presence of serum decreases this effect. No inhibition took place of the agglutination of appropriate cells with anti- $A$, anti- $B$, naturally occurring anti- $M$ or anti- $N$ sera, or of the sensitization of $D$. positive cells with an incomplete anti- $D$ serum.

No evidence was found in further experiments that a change of $p \mathrm{H}$ was inhibiting the $R h$ agglutination, or that the anti-Rh agglutinins became attached to the red cell antigens without the usual subsequent cell agglutination. But evidence was obtained suggesting that the acid citrate was absorbed by the red cells and prevented their reaction with the agglutinins. 